\title{
https://doi.org/10.2514/6.2022-1103
}

\section{Knock propensity in a thermally inhomogeneous DME/air mixture: a DNS study}

\author{
Minh Bau Luong * and Hong G. Im ${ }^{\dagger}$ \\ King Abdullah University of Science and Technology (KAUST), Clean Combustion Research Center, Thuwal \\ 23955-6900, Saudi Arabia
}

\begin{abstract}
Superknock propensity in a stoichiometric dimethyl-ether (DME)/air mixture with temperature inhomogeneities under realistic IC engine conditions is investigated using two-dimensional direct numerical simulations (DNS). The developing detonation regime at different conditions is identified by varying the initial mean temperature lying in the low-, intermediate-, and high-temperature chemistry regimes, the level of temperature fluctuations, and its characteristic length scale. We found that the cool flame from the first-stage ignition induces synergistic effects on promoting knock tendency. First, it significantly decreases a minimum run-up distance requirement for developing detonation due to the low-temperature chemistry. Second, analyzing the temporal evolution of the spatial distribution of ignition delay field reveals that the heat release rate from the first-stage ignition effectively modifies the initial field of the ignition delay time, thereby shifting the mixture towards the developing detonation regime. The interaction of multiple ignition kernels is also found to play an important role in enhancing the onset of detonation.
\end{abstract}

\section{Introduction}

Modern internal combustion (IC) engines operate under elevated pressure enabled by downsized boosted technologies to achieve higher thermal efficiency, higher power-density output per volume, and ultra-low emission. However, being operated at elevated pressure and high-load conditions leads to a higher propensity of undesired preignition, knock, and even superknock [1-8]. Superknock is characterized as a developing detonation process featuring excessive pressure oscillations and extremely high-pressure amplitudes that can damage combustion-chamber components [7, 9-20, 20]. Improved understandings of the superknock propensity and a reliable criterion to predict it are needed to prevent destructive operation of combustion devices [2, 4, 5, 7, 21-27]. Therefore, first-principle high-fidelity direct numerical simulations (DNS) with the capability of fully resolving all temporal and spatial scales and the complex interaction of thermochemistry and turbulence under extreme high-load operating conditions are employed to unravel the mechanism of abnormal combustion phenomena in combustion devices such as IC engines, shock tubes, and rapid compression machines (RCM) [2,3].

In pioneering work [28], Zeldovich classified the five possible modes of an autoignition front propagating in a thermally inhomogeneous mixture: homogeneous thermal explosion, supersonic auto-ignitive detonation, developing and developed detonation, subsonic auto-ignitive front propagation, and normal flame deflagration. The classification was made based on the relative ratio of the spontaneous propagation speed of an ignition front, $S_{s p}$, to the laminar flame speed, $S_{s p} / S_{L}$, and to the sound speed, $S_{s p} / a$, of the local mixture. $S_{s p}$ is determined by the spatial gradient of the ignition delay times, i.e., $S_{s p}=\left|\nabla \tau_{i g}\right|^{-1}[28]$.

Following Zeldovich's theory, Gu and Bradley [29-31] quantitatively mapped different ignition modes into a regime diagram expressed in terms of two non-dimensional parameters, $\xi$ and $\varepsilon$, which are defined as:

$$
\begin{gathered}
\xi=a / S_{s p}, \\
\varepsilon=\left(r_{h s} / a\right) / \tau_{e},
\end{gathered}
$$

where $\varepsilon$ is defined as the ratio of the transit time, $r_{h s} / a$, of the acoustic wave through an igniting hot spot of a radius, $r_{h s}$, to the excitation time, $\tau_{e}$, in which most of the chemical energy is released. $\tau_{e}$ is defined as the time interval between 


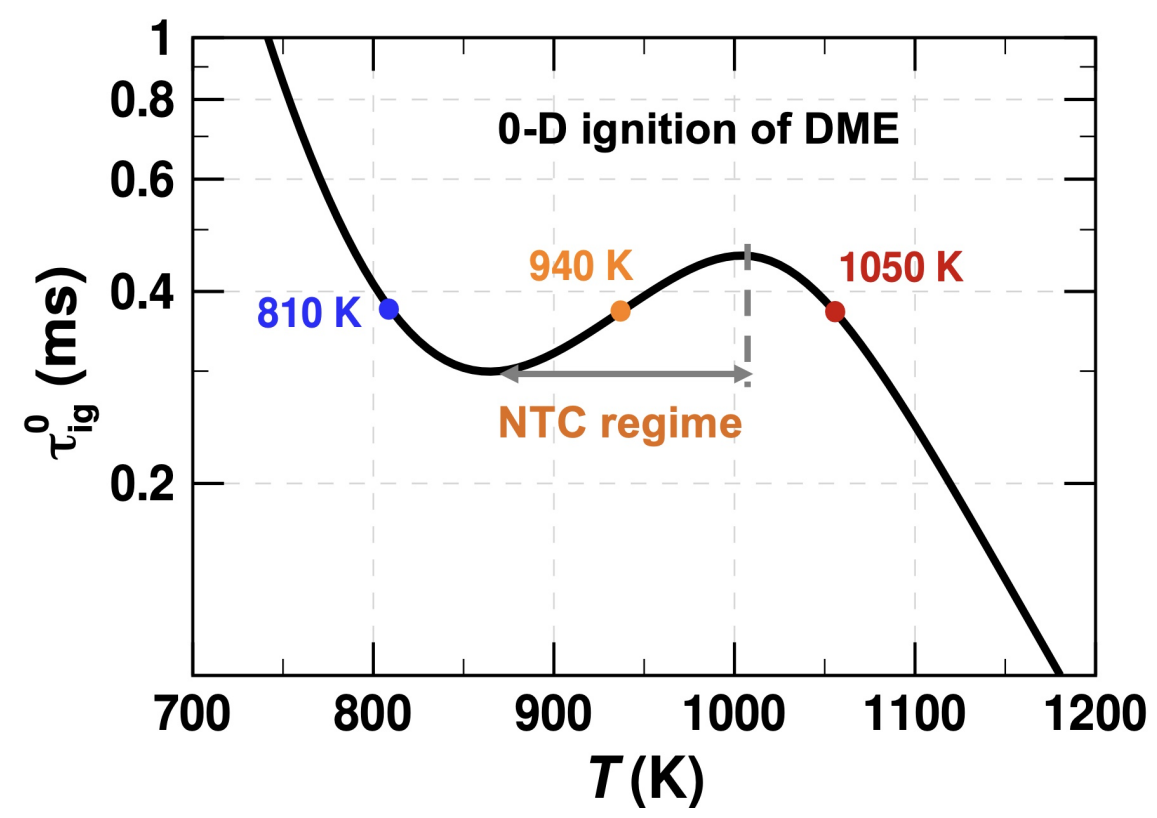

Fig. 1 The 0-D homogeneous ignition delay time, $\tau_{i g}$ as a function of temperature for a DME/air mixture at $\phi$ of 1 , and pressure of $40 \mathrm{~atm}$.

$5 \%$ of the peak heat release rate (HRR) and the peak HRR. In general, superknock is expected when $\xi$ ranges between 1 to $O(10)$ quantity $[2,32-34]$ that allows the coupling and mutual reinforcement between the acoustic wave and the autoigniting front, leading to developing detonation featured by an extremely high-pressure amplitude.

The $\xi-\varepsilon$ diagram has been widely adopted in one-dimensional (1-D) DNS studies [11, 14, 35-45], while a few multi-dimensional DNS studies have been conducted due mainly to computational expense [2-4, 46-48].

Generally, it is found that the fuels exhibiting a sing-stage ignition, e.g., ethanol and gasoline, are found to be more resistant to superknock development due to their high octane number. On the contrary, the fuels exhibiting a two-stage ignition, e.g., $n$-heptane and dimethyl-ether (DME), are more susceptible to superknock development due to their low octane number (high reactivity). The low-temperature chemistry is attributed to induce a unique ignition characteristic called the negative temperature coefficient (NTC) behavior that complicates the knock propensity of two-stage ignition fuels. However, the fundamental understanding of the ignition process of two-stage ignition fuels with the presence of thermal fluctuation are not well understood.

To this end, the objective of this study is to provide better understandings of the mechanism of detonation development in a thermally inhomogeneous DME/air mixture exhibiting two-stage ignition processes. Two-dimensional simulations are performed by varying the initial mean temperature lying in the low-, intermediate-, and high-temperature chemistry regimes, the level of temperature fluctuations, and its characteristic length scale. DME exhibiting a strong negative temperature coefficient (NTC) behavior with a two-stage ignition process is used as a representative of NTC fuels.

\section{Numerical methods and initial conditions}

The KAUST Adaptive Reacting Flow Solver (KARFS) [2, 3, 41, 49] is used to solves the fully compressible Navier-Stokes, species and energy equations for gaseous mixtures. An eighth-order finite-difference scheme was employed for the spatial discretization of the diffusive terms. The convective terms were discretized using a seventh-order mapped weighted essentially non-oscillatory scheme to capture shocks waves. The solution was advanced in time using a second-order operator-splitting strategy with a fourth-order explicit Runge-Kutta method for transport and variable-order backward differentiation formulas for chemistry. Cantera [50] is linked to KARFS for evaluating reaction rates and thermodynamic and mixture-averaged transport properties. Periodic boundary conditions were imposed in all

\footnotetext{
*Postdoctoral fellow, Clean Combustion Research Center, KAUST, AIAA Member, Email: minhbau.luong @kaust.edu.sa

${ }^{\dagger}$ Professor, Clean Combustion Research Center, KAUST, AIAA Associate fellow.
} 

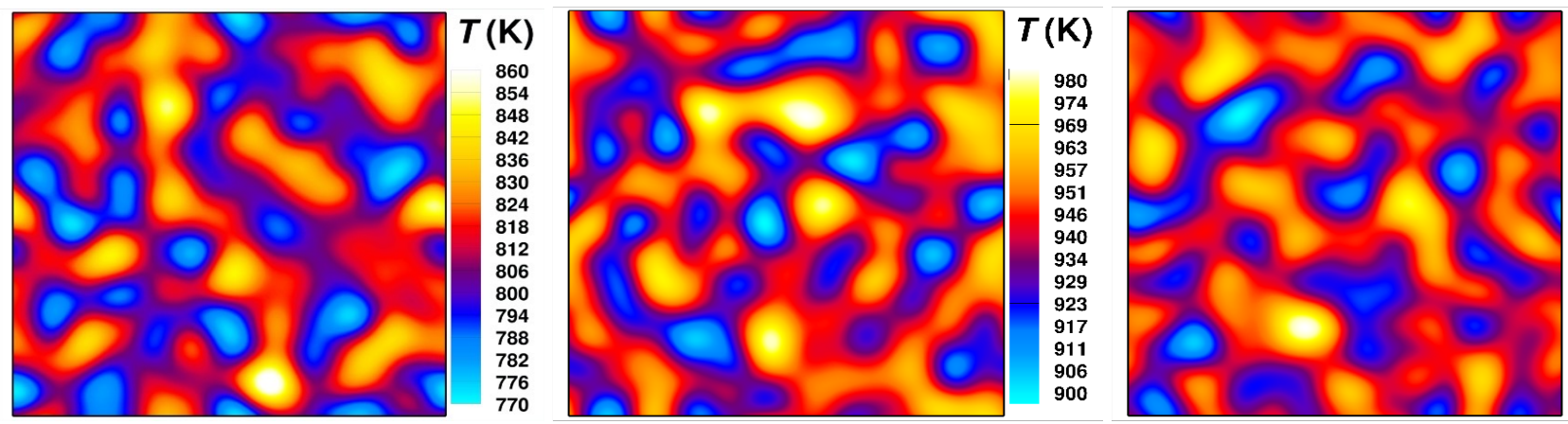

Fig. 2 Representative initial field of temperature at three different mean temperature of $810 \mathrm{~K}, 940 \mathrm{~K}$, and 1050 $\mathrm{K}$ (from left to right, respectively) with $l_{T}$ of $5 \mathrm{~mm}$ and $T^{\prime}$ of $15 \mathrm{~K}$.

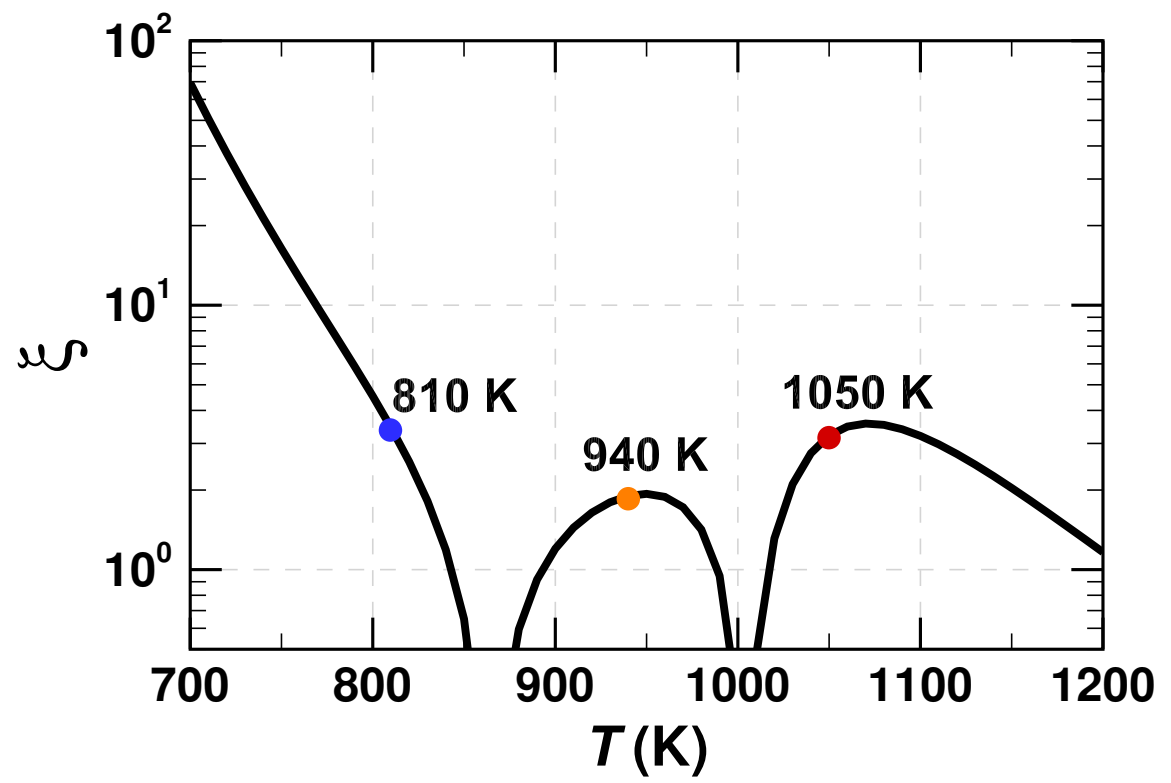

Fig. $3 \xi$ as a function of temperature with $\partial T / \partial r=-2 \mathrm{~K} / \mathbf{m m}$ for a DME/air mixture at $\phi$ of 1.0 , and pressure of 40 atm.

directions such that ignition occurs in a constant volume.

DME exhibiting a pronounced NTC behavior is chosen as a representative two-stage ignition fuel. A DME skeletal mechanism consisting of 39 species and 175 reactions [51] was adopted, which was validated over a wide range of equivalence ratio, pressure, and temperature conditions [51]. The skeletal mechanism for DME oxidation was developed from the detailed mechanism consisting of 55 species and 290 elementary reactions. More details can be found in $[1,51,52]$.

A systematically parametric set of two-dimensional simulations with the presence of spatial temperature fluctuations is conducted under realistic engine conditions. The initial mean temperature, the level of temperature fluctuations, and its characteristic length scale are varied to identify the developing detonation regime in a thermally inhomogeneous DME/air mixture. All the simulations are performed with initial uniform equivalence ratio, $\phi_{0}$, and pressure, $P_{0}$, of 1 and $40 \mathrm{~atm}$, respectively, which represent the near top-dead-center conditions of an IC engine [1, 2, 2, 21, 53-61]. As shown in Fig. 1, three initial mean temperatures of 810, $940 \mathrm{~K}$, and $1050 \mathrm{~K}$ lying in the low-, intermediate-, and high-temperature chemistry regime, respectively, are chosen.

The initial isotropic temperature fields are prescribed by an energy spectrum function of Passot and Pouquet [52-56, 59, 61-64]. A quiescent initial velocity field is imposed for all DNS cases to isolate the effect of temperature fluctuations as in [2]. Representative initial temperature fields at three different mean temperature of $810 \mathrm{~K}, 940 \mathrm{~K}$, and $1050 \mathrm{~K}$ are shown in Fig. 2. 

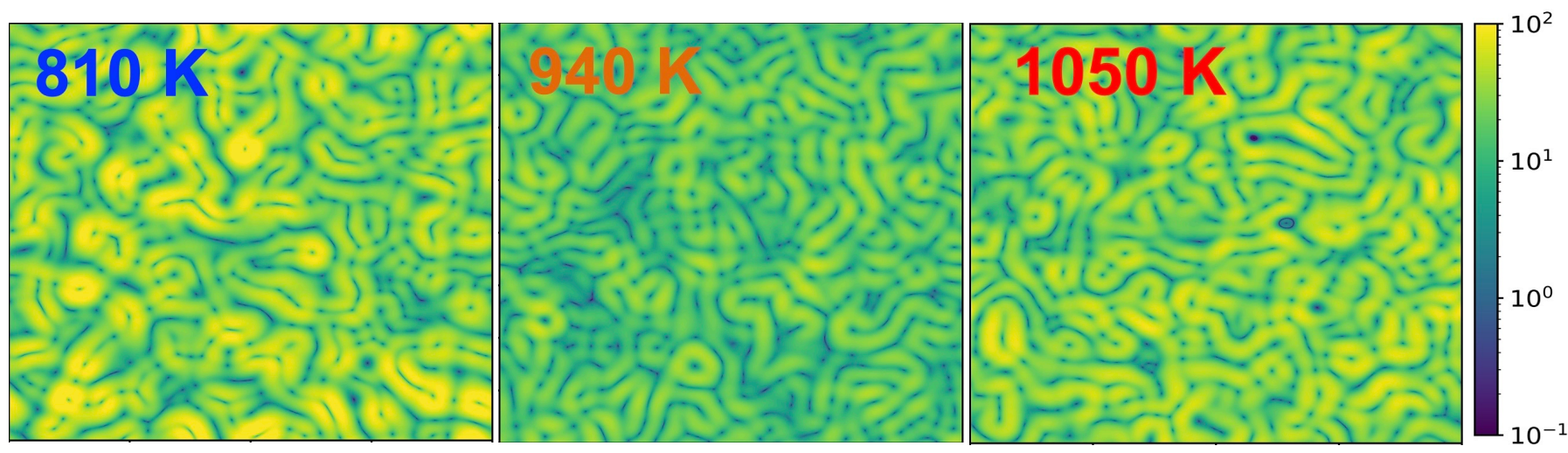

Fig. 4 Representative initial field of $\xi$ for three different mean temperature of $810 \mathrm{~K}, 940 \mathrm{~K}$, and $1050 \mathrm{~K}$ with $l_{T}$ of $5 \mathrm{~mm}$ and $T^{\prime}$ of $15 \mathrm{~K}$.

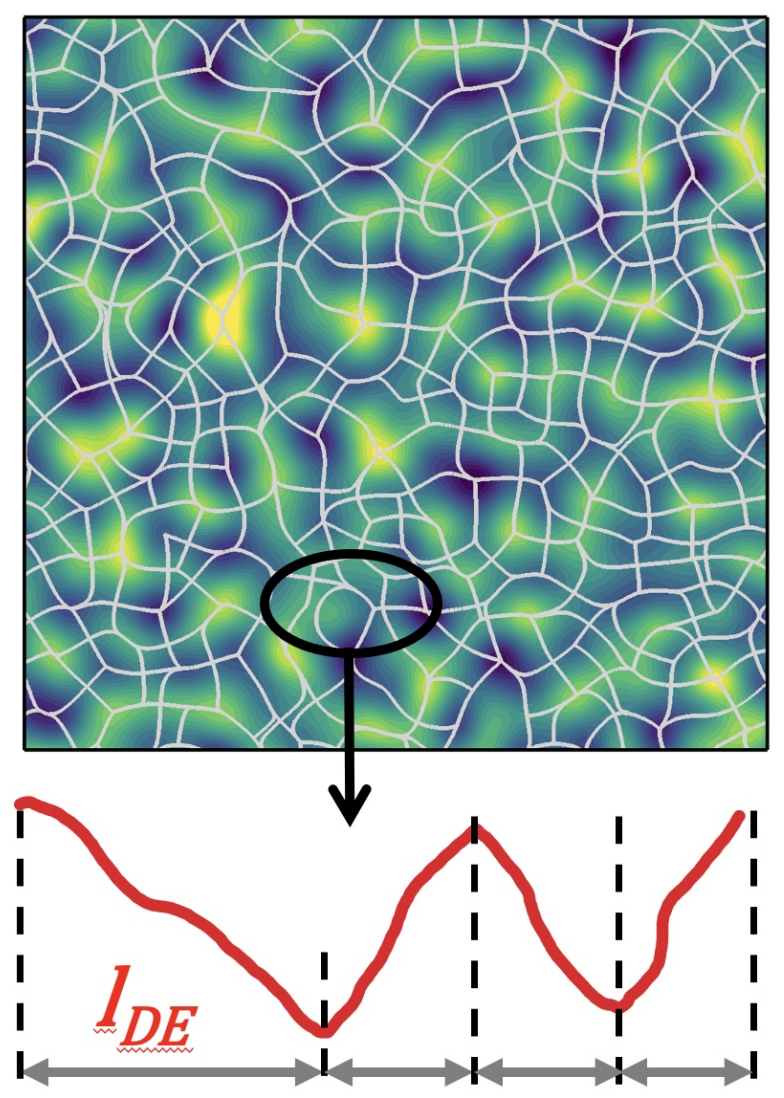

Fig. 5 Representative 2-D contour of temperature field with $T_{0}$ of $1050 \mathrm{~K}, T^{\prime}$ of $15 \mathrm{~K}$, and $l_{T}$ of $5 \mathrm{~mm}$ overlaid by the dissipation elements. The white lines mark the boundary between the dissipation elements.

\section{Results and discussion}

To ensure a mixture falling into the developing detonation regime, the range of $\xi$ is found to be on the order of 1 to $O(10)$, and $\varepsilon>1$. The computed value of $\xi$ with abs $(\partial T / \partial r)=2 \mathrm{~K} / \mathrm{mm}$ is plotted as a function of temperature for a DME/air mixture at $\phi$ of 1 , and pressure of $40 \mathrm{~atm}$ in Fig. 3. Note that the temperature gradient, abs $(\partial T / \partial r)$, on the order of 1 to $\sim O(10) \mathrm{K} / \mathrm{mm}$ is typically encountered in IC engine conditions. The value, abs $(\partial T / \partial r)=2 \mathrm{~K} / \mathrm{mm}$, has been widely used to evaluate the knock propensity of a fuel under engine conditions [65]. Given the range of $\xi$ 
between 1 to $O(10)$ being prone to detonation development, Fig 3 suggests that three cases with different initial mean temperatures at the same temperature gradient level have the same propensity of detonation development under the conditions considered in this study.

In line with the calculation of $\xi$ in Fig. 3 suggested by a simplified 0D model, the developing detonation regime in multi-dimensional DNS cases can also be identified by choosing a proper set of $T^{\prime}$ and $l_{T}$ values. By following the procedure in [2], we found that with $l_{T}$ of $5 \mathrm{~mm}$, all the three cases are prone to a strong detonation if a proper level of $T^{\prime}$ distribution is chosen. $l_{T}$ of $5 \mathrm{~mm}$ is determined through the analysis of the dissipation element theory $[2,27,66]$. Figure 5 shows a representative 2-D contour of temperature field with $T_{0}$ of $1050 \mathrm{~K}, T^{\prime}$ of $15 \mathrm{~K}$, and $l_{T}$ of $5 \mathrm{~mm}$ decomposed into dissipation elements. According to Peters et al. [27, 66], the temperature field is subdivided into the dissipation elements over which the temperature profile is monotonic, ranging from the peak to the trough of each dissipation element as schematically shown in Fig. 5. For isotropic temperature field fluctuations, Peters et al. $[27,66]$ found that the size of hot spot, $r_{h s}$, is comparable with the mean distance of the dissipation elements, $l_{D E}$, and approximated as $l_{D E} \approx 2 \lambda_{T}$, where $\lambda_{T}$ is the Taylor mixing scale [27]. In the multi-dimensional problems, $l_{D E}$ is believed to be a minimum size of a hot spot of unburned reactants required so that it allows a sufficient run-up distance of detonation development [2].

While not extensively discussed here, we found that due to the non-monotomic behavior of $\tau_{i g}$ as a function of temperature in the NTC regime, the distribution of dissipation elements based on the temperature field is not exactly the same with that based on $\tau_{i g}$ field when the temperature field is widely distributed across low-to-high temperature regimes, i.e., at $T_{0} \sim 864 \mathrm{~K}, T_{0} \sim 1004 \mathrm{~K}$, and/or with $T^{\prime}>20 \mathrm{~K}$ for the condition considered in this study. As such, we found that $l_{D E}$ determined through the distribution of the $\tau_{i g}$ field, which directly affects the $\xi$ distribution, allows a better prediction of the detonation propensity for the NTC fuels (not shown here) [67]. As shown in Fig. 4, the full detailed information of spatial distribution of $\xi$ is computed for each initial temperature field with $l_{T}$ of $5 \mathrm{~mm}$ and $T^{\prime}$ of $15 \mathrm{~K}$. As such, the corresponding statistical quantities of $\xi$ are also attained to evaluate the knock propensity and knock intensity levels $[2,3]$ that will be verified by a series of the 2D DNS results.
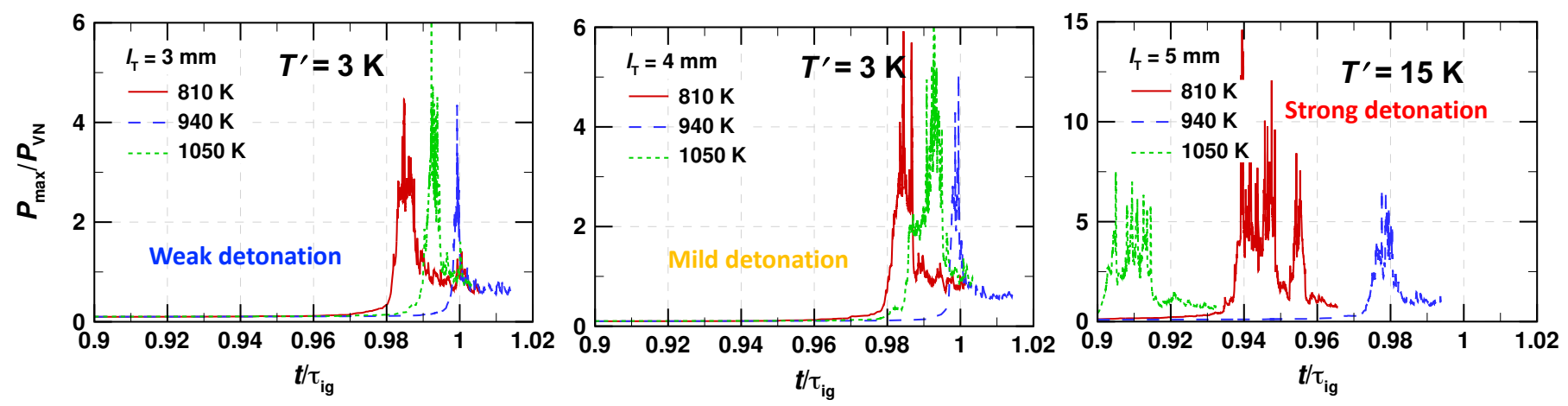

Fig. 6 Temporal evolution of the normalized maximum pressure, $P_{\max } / P_{V N}$, with $l_{T}$ of $3 \mathrm{~mm}, 4 \mathrm{~mm}$, and $5 \mathrm{~mm}$ and different levels of temperature fluctuations.

The results of the temporal evolution of the maximum pressure in Fig. 6, are consistent with the expectation from the initial field of $\xi$ in Fig. 3. Particularly, the peak pressure and the duration of $P_{\max }$ reaching the von Neumann pressure, $\sim P_{V N}$, increase with increasing $T^{\prime}$, indicating a higher detonation propensity. The cases with $T^{\prime}$ of $15 \mathrm{~K}$ and $l_{T}$ of 5 $\mathrm{mm}$ exhibits a strong detonation process regardless of the initial mean temperature lying in three different chemistry regimes. However, decreasing the length scale of temperature fluctuations, $l_{T}$ from $5 \mathrm{~mm}$ to $3 \mathrm{~mm}$, hence decreasing the run-up distance for developing detonation, alleviates knock intensity for all three cases regardless of the increment of the mean temperature $T_{0}$ from $810 \mathrm{~K}$ to $1050 \mathrm{~K}$.

The contours of pressure and temperature are shown in Fig. 7 for the case with $T_{0}$ of $810 \mathrm{~K}$ and $l_{T}$ of $3 \mathrm{~mm}$. Figure 7 reveals that a strong autoignition process followed by developing detonation waves at the end of combustion process when the most of the mixture is consumed. There is not enough a run-up distance that allows a stable detonation front to form at the onset of the detonation development. Note that $T^{\prime}$ of $3 \mathrm{~K}$ is intentionally chosen to maximize the detonating tendency for the cases with small $l_{T}$. In contrast, by increasing $l_{T}$ to $5 \mathrm{~mm}$ and imposing a high level of temperature fluctuation, $T^{\prime}$ of 15 , a few strong detonation waves are already formed at the early time at which a large portion of the unburned fuel/air mixture (low temperature) still remains. Interestingly, even with a larger $T^{\prime}>15 \mathrm{~K}$ and the mean $\xi$ 

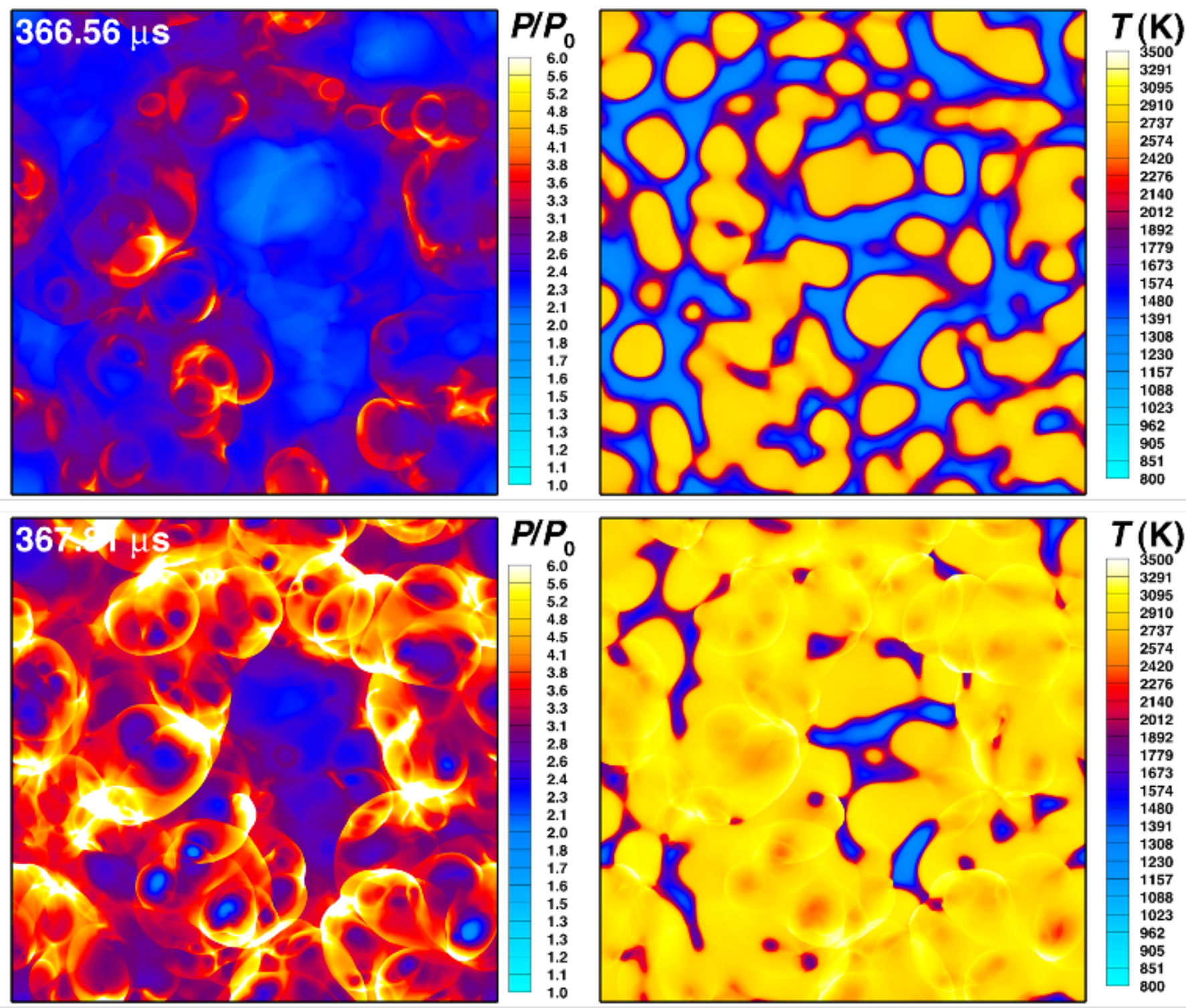

Fig. 7 Contour of pressure and temperature at the onset of detonation (first row), and at the main of ignition process (second row), for the case with $T_{0}$ of $810 \mathrm{~K}, l_{T}$ of $3 \mathrm{~mm}$, and $T^{\prime}$ of $15 \mathrm{~K}$.

value $\gg 10$, a strong detonation is still observed for the case with $T_{0}$ of $810 \mathrm{~K}$ (not shown here) [67].

By performing further in-depth analysis, we found that the cool flame from the first-stage ignition induces twofold effects on promoting knock tendency. First, it significantly decreases a minimum run-up distance requirement for developing detonation [67]. Second, by analyzing of the temporal evolution of the spatial distribution of ignition delay field, we also found that the heat release rate from the first-stage ignition effectively modifies the initial $\tau_{i g}$ field, thereby shifting the mixture towards the developing detonation regime. 

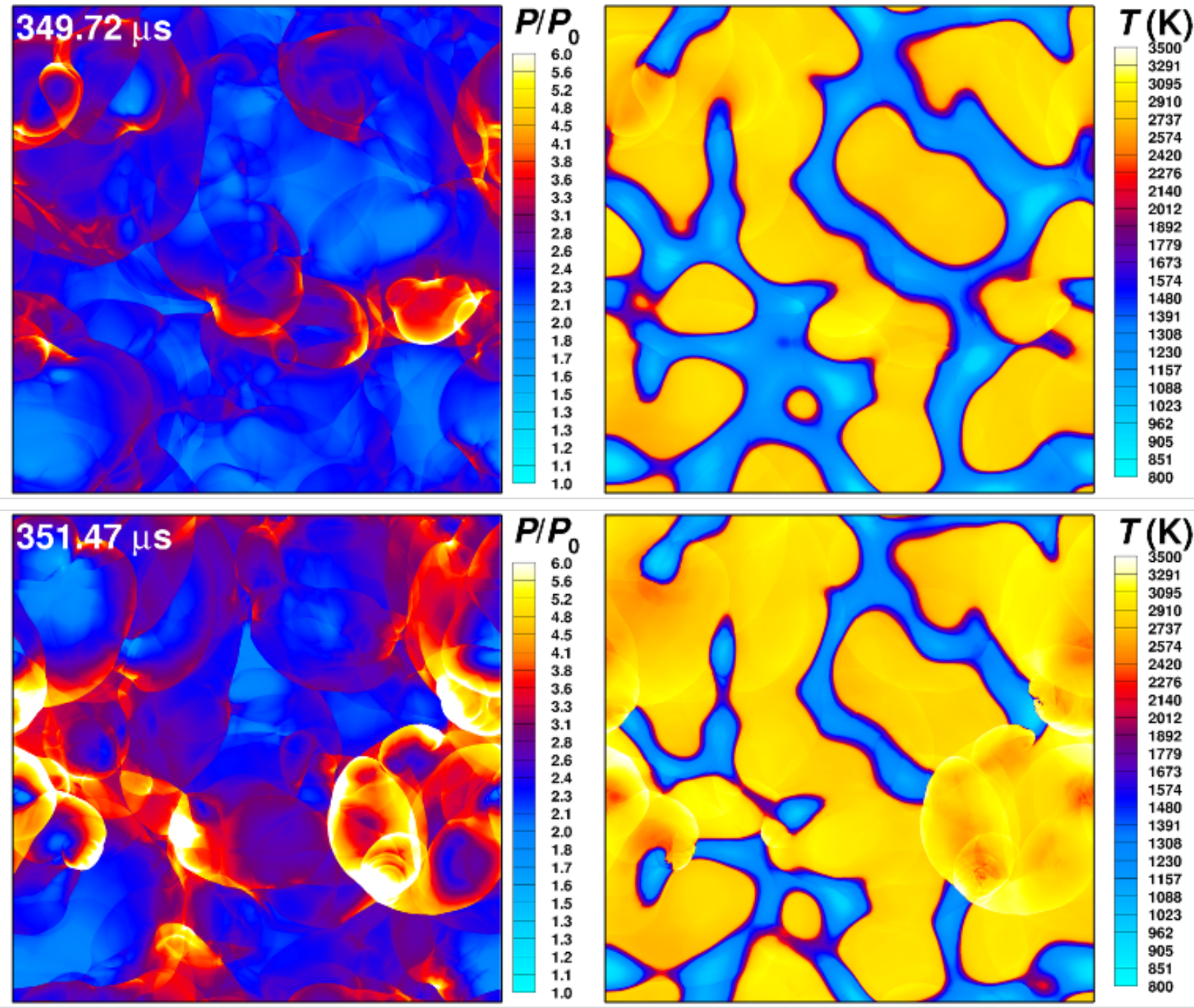

\begin{tabular}{|l|l|}
\multicolumn{1}{|l}{ ( K $)$} \\
\hline 3500 \\
\hline 3291 \\
\hline 3095 \\
\hline 2910 \\
2737 \\
2574 \\
2420 \\
2276 \\
2140 \\
2012 \\
1892 \\
1779 \\
1673 \\
1574 \\
1480 \\
1391 \\
1308 \\
1230 \\
1157 \\
1088 \\
1023 \\
962 \\
905 \\
\hline 851 \\
800 \\
\hline
\end{tabular}

Fig. 8 Contour of pressure and temperature at the onset of detonation (first row), and at later time when several detonation have formed (second row), for the case with $T_{0}$ of $810 \mathrm{~K}, l_{T}$ of $5 \mathrm{~mm}$, and $T^{\prime}$ of $15 \mathrm{~K}$. 


\section{Conclusion}

The existence of the negative temperature coefficient (NTC) behavior of two-stage ignition fuels is known to complicate the developing detonation process. This study focuses on how the low-temperature chemistry affects the run-up distance of detonation when the initial mean temperature lies in different temperature regimes. A series of two-dimensional direct numerical simulations (DNS) under realistic engine conditions are performed by varying the initial mean temperature lying in the low-, intermediate-, and high-temperature chemistry regimes, the level of temperature fluctuations, and its characteristic length scale. Dimethyl ether (DME) exhibiting a representative two-stage ignition process, and a strong NTC behavior is adopted as a fuel. We found that the minimum running distance allowing detonation formation in the low-temperature regime is within the same order of magnitude as that in the intermediate- and high-temperature regime. Particularly, the DNS results reveal that at the same characteristic length scale of temperature field, the low-temperature cases can form detonation waves, leading to excessive pressure oscillations and extremely high-pressure spikes. In addition, by analyzing of the temporal evolution of the spatial distribution of ignition delay field, we also found that the heat release rate from the first-stage ignition effectively modifies the initial ignition delay field, thereby shifting the mixture towards the developing detonation regime.

\section{Acknowledgments}

This work was sponsored by the research funding from King Abdullah University of Science and Technology (KAUST). This research used the computational resources of the KAUST Supercomputing Laboratory (KSL).

\section{References}

[1] Luong, M. B., Hernández Pérez, F. E., and Im, H. G., "Prediction of ignition modes of NTC-fuel/air mixtures with temperature and concentration fluctuations," Combust. Flame, Vol. 213, 2020, pp. 382-393.

[2] Luong, M. B., Desai, S., Hernández Pérez, F. E., Sankaran, R., Johansson, B., and Im, H. G., "A statistical analysis of developing knock intensity in a mixture with temperature inhomogeneities," Proc. Combust. Inst., Vol. 38, 2021, pp. 5781-5789.

[3] Luong, M. B., Desai, S., Hernández Pérez, F. E., Sankaran, R., Johansson, B., and Im, H. G., "Effects of turbulence and temperature fluctuations on knock development in an ethanol/air mixture," Flow Turbul. Combust., Vol. 106, 2021, pp. 575-595.

[4] Luong, M. B., and Im, H. G., "Direct Numerical Simulation of Preignition and Knock in Engine Conditions," Advances in Energy and Combustion: Green Energy and Technology, Springer, 2022, pp. 311-336. https://doi.org/https://doi.org/10.1007/978-98116-2648-7_14.

[5] Luong, M. B., and Im, H. G., "Direct Numerical Simulation of Preignition and Knock in Engine Conditions," Engines and Fuels for Future Transport, Energy, Environment, and Sustainability, Springer, 2022. https://doi.org/https://doi.org/10.1007/978-98116-8717-4_15.

[6] Ali, M. J. M., Luong, M. B., Sow, A., Hernández Pérez, F. E., and Im, H. G., "Probabilistic Approach to Predict Abnormal Combustion in Spark Ignition Engines," SAE paper, 2018, pp. 2018-01-1722.

[7] Figueroa-Labastida, M., Luong, M. B., Badra, J., Im, H. G., and Farooq, A., "Experimental and computational studies of methanol and ethanolpreignition behind reflected shock waves," Combust. Flame, Vol. 234, 2021, p. 111621.

[8] Zhang, J., Luong, M. B., Hernández Pérez, F. E., Han, D., Im, H. G., and Huang, Z., "Exergy loss of DME/air mixtures and ethanol/air mixtures with temperature and concentration fluctuations under HCCI/SCCI conditions: A DNS study," Combust. Flame, Vol. 226, 2019, pp. 334-346.

[9] Pan, J., Zheng, Z., Wei, H., Pan, M., Shu, G., and Liang, X., “An experimental investigation on pre-ignition phenomena: Emphasis on the role of turbulence," Proceedings of the Combustion Institute, Vol. 38, No. 4, 2021, pp. 5801-5810.

[10] Pan, J., Dong, S., Wei, H., Li, T., Shu, G., and Zhou, L., "Temperature gradient induced detonation development inside and outside a hotspot for different fuels," Combust. Flame, Vol. 205, 2019, pp. 269-277.

[11] Pan, J., Wei, H., Shu, G., and Chen, R., "Effect of pressure wave disturbance on auto-ignition mode transition and knocking intensity under enclosed conditions," Combust. Flame, Vol. 185, 2017, pp. 63-74.

[12] Pan, J., Hu, Z., Wei, H., Pan, M., Liang, X., Shu, G., and Zhou, L., "Understanding strong knocking mechanism through high-strength optical rapid compression machines," Combust. Flame, Vol. 202, 2019, pp. 1-15. 
[13] Pan, J., Shu, G., Zhao, P., Wei, H., and Chen, Z., "Interactions of flame propagation, auto-ignition and pressure wave during knocking combustion," Combust. Flame, Vol. 164, 2016, pp. 319-328.

[14] Pan, J., Wei, H., Shu, G., Chen, Z., and Zhao, P., "The role of low temperature chemistry in combustion mode development under elevated pressures," Combust. Flame, Vol. 174, 2016, pp. 179-193.

[15] Wei, H., Zhao, J., Zhang, X., Pan, J., Hua, J., and Zhou, L., "Turbulent flame-shock interaction inducing end-gas autoignition in a confined space," Combust. Flame, Vol. 204, 2019, pp. 137-141.

[16] Yu, Z., Zhang, H., and Dai, P., "Autoignition and detonation development induced by temperature gradient in n-C7H16/air/H2O mixtures," Physics of Fluids, Vol. 33, No. 1, 2021, p. 017111.

[17] Shi, H., Tang, Q., Uddeen, K., Magnotti, G., and Turner, J., "Optical diagnostics and multi-point pressure sensing on the knocking combustion with multiple spark ignition," Combustion and Flame, Vol. 236, 2022, p. 111802.

[18] Shi, H., Tang, Q., Uddeen, K., Johansson, B., Turner, J., and Magnotti, G., "Effects of multiple spark ignition on engine knock under different compression ratio and fuel octane number conditions," Fuel, 2021, p. 122471.

[19] Uddeen, K., Shi, H., Tang, Q., and Turner, J., "Investigations into the Effects of Spark Plug Location on Knock Initiation by using Multiple Pressure Transducers,” SAE International, 2021.

[20] Shi, H., Uddeen, K., An, Y., Pei, Y., and Johansson, B., "Multiple spark plugs coupled with pressure sensors: A new approach for knock mechanism study on SI engines," Energy, Vol. 227, 2021, p. 120382.

[21] Luong, M. B., Figueroa-Labastida, M., Pérez, F. E. H., Farooq, A., and Im, H. G., "Prediction of preignition tendency in shock tubes," Submitted to Combust. Flame, 2021.

[22] Im, H. G., Pal, P., Wooldridge, M. S., and Mansfield, A. B., "A Regime Diagram for Autoignition of Homogeneous Reactant Mixtures with Turbulent Velocity and Temperature Fluctuations," Combust. Sci. Technol., Vol. 187, 2015, pp. 1263-1275.

[23] Bates, L., Bradley, D., Paczko, G., and Peters, N., "Engine hot spots: Modes of auto-ignition and reaction propagation," Combust. Flame, Vol. 166, 2016, pp. 80-85.

[24] Bates, L., Bradley, D., Gorbatenko, I., and Tomlin, A. S., "Computation of methane/air ignition delay and excitation times, using comprehensive and reduced chemical mechanisms and their relevance in engine autoignition," Combust. Flame, Vol. 185, 2017, pp. 105-116.

[25] Gautam T Kalghatgi, and Derek Bradley, "Pre-ignition and 'super-knock' in turbo-charged spark-ignition engines," Int. J. Engine Res., Vol. 13, 2012, pp. 399-414.

[26] Rudloff, J., Zaccardi, J.-M., Richard, S., and Anderlohr, J., "Analysis of pre-ignition in highly charged SI engines: Emphasis on the auto-ignition mode," Proceedings of the Combustion Institute, Vol. 34, No. 2, 2013, pp. 2959-2967.

[27] Peters, N., Kerschgens, B., and Paczko, G., "Super-Knock Prediction Using a Refined Theory of Turbulence," SAE Int. J. Engines, Vol. 6, 2013, pp. 953-967.

[28] Zeldovich, Y. B., "Regime classification of an exothermic reaction with nonuniform initial conditions," Combust. Flame, Vol. 39, 1980, pp. 211-214.

[29] Bradley, D., “'Hot spots’ and gasoline engine knock,” J. Chem. Soc., Faraday Trans., Vol. 92, 1996, pp. $2959-2964$.

[30] Bradley, D., Morley, C., Gu, X. J., and Emerson, D. R., “Amplified Pressure Waves During Autoignition: Relevance to CAI Engines," SAE Technical Paper, 2002, pp. 2002-01-2868.

[31] Gu, X., Emerson, D., and Bradley, D., "Modes of reaction front propagation from hot spots," Combust. Flame, Vol. 133, 2003, pp. 63-74.

[32] Su, J., Dai, P., and Chen, Z., "Detonation development from a hot spot in methane/air mixtures: Effects of kinetic models," Int. J. Engine Res., Vol. 22, No. 8, 2020, pp. 2597-2606.

[33] Gao, Y., Dai, P., and Chen, Z., "Numerical studies on autoignition and detonation development from a hot spot in hydrogen/air mixtures," Combustion Theory and Modelling, Vol. 24, 2020, pp. 245-261.

[34] Dai, P., Chen, Z., Gan, X., and Liberman, M. A., "Autoignition and detonation development from a hot spot inside a closed chamber: Effects of end wall reflection," Proceedings of the Combustion Institute, Vol. 38, 2021, pp. 5905-5913. 
[35] Dai, P., Chen, Z., Chen, S., and Ju, Y., "Numerical experiments on reaction front propagation in n-heptane/air mixture with temperature gradient," Proc. Combust. Inst., Vol. 35, 2015, pp. 3045-3052.

[36] Yu, H., and Chen, Z., "End-gas autoignition and detonation development in a closed chamber," Combust. Flame, Vol. 162, 2015, pp. 4102-4111.

[37] Dai, P., Qi, C., and Chen, Z., "Effects of initial temperature on autoignition and detonation development in dimethyl ether/air mixtures with temperature gradient," Proc. Combust. Inst., Vol. 36, 2017, pp. 3643-3650.

[38] Terashima, H., Matsugi, A., and Koshi, M., "Origin and reactivity of hot-spots in end-gas autoignition with effects of negative temperature coefficients: Relevance to pressure wave developments," Combust. Flame, Vol. 184, 2017, pp. 324-334.

[39] Wei, H., Chen, C., Shu, G., Liang, X., and Zhou, L., "Pressure wave evolution during two hotspots autoignition within end-gas region under internal combustion engine-relevant conditions," Combust. Flame, Vol. 189, 2018, pp. 142-154.

[40] Sow, A., Lee, B. J., Hernández Pérez, F. E., and Im, H. G., "Detonation onset in a thermally stratified constant volume reactor," Proc. Combust. Inst., Vol. 37, 2019, pp. 3529-3536.

[41] Desai, S., Yu, J. K., Song, W., Luong, M. B., Hernández Pérez, F. E., Sankaran, R., and Im, H. G., "Direct numerical simulations of reacting flows with shock waves and stiff chemistry using many-core/GPU acceleration," Computers \& Fluids, Vol. 215, 2021, p. 104787.

[42] Desai, S., Sankaran, R., and Im, H. G., "Auto-ignitive deflagration speed of methane $\left(\mathrm{CH}_{4}\right)$ blended dimethyl-ether (DME)/air mixtures at stratified conditions," Combust. Flame, Vol. 211, 2020, pp. 377 - 391.

[43] Desai, S., Sankaran, R., and Im, H. G., "Unsteady deflagration speed of an auto-ignitive dimethyl-ether (DME)/air mixture at stratified conditions," Proc. Combust. Inst., Vol. 37, 2019, pp. 4717 - 4727.

[44] Luong, M. B., Figueroa-Labastida, M., Tingas, E.-A., Sow, A., Pérez, F. E. H., Badra, J., Farooq, A., and Im, H. G., "Heat capacity effect on ethanol preignition in a shock tube," 27th International Colloquium on the Dynamics of Explosions and Reactive Systems, ICDERS, 2019, p. Paper 297.

[45] Pal, P., Mansfield, A. B., Arias, P. G., Wooldridge, M. S., and Im, H. G., "A computational study of syngas auto-ignition characteristics at high-pressure and low-temperature conditions with thermal inhomogeneities," Combust. Theory Model., Vol. 187, 2015, pp. 587-601.

[46] Akita, K., Morii, Y., Nakamura, H., Tezuka, T., and Maruta, K., "2D computations of FREI with cool flames for n-heptane/air mixture," Proc. Combust. Inst., Vol. 38, No. 2, 2021, pp. 2247-2255.

[47] Morii, Y., Dubey, A. K., Nakamura, H., and Maruta, K., “Two-dimensional laboratory-scale DNS for knocking experiment using n-heptane at engine-like condition,” Combust. Flame, Vol. 223, 2021, pp. 330-336.

[48] Zhang, X., Wei, H., Zhou, L., Cai, X., and Deiterding, R., "Relationship of flame propagation and combustion mode transition of end-gas based on pressure wave in confined space," Combust. Flame, Vol. 214, 2020, pp. 371-386.

[49] Hernández Pérez, F. E., Mukhadiyev, N., Xu, X., Sow, A., Lee, B. J., Sankaran, R., and Im, H. G., "Direct numerical simulations of reacting flows with detailed chemistry using many-core/GPU acceleration," Computers \& Fluids, Vol. 173, 2018, pp. 73-79.

[50] Goodwin, D. G., Moffat, H. K., and Speth, R. L., "Cantera: An object-oriented software toolkit for chemical kinetics, thermodynamics, and transport processes," Caltech, Pasadena, CA, 2009.

[51] Bhagatwala, A., Luo, Z., Shen, H., Sutton, J. A., Lu, T., and Chen, J. H., "Numerical and experimental investigation of turbulent DME jet flames," Proc. Combust. Inst., Vol. 35, 2015, pp. 1157-1166.

[52] Luong, M. B., Hernández Pérez, F. E., Sow, A., and Im, H. G., "Prediction of Ignition Regimes in DME/Air Mixtures with Temperature and Concentration Fluctuations," AIAA SciTech 2019 Forum, 2019, pp. https://doi.org/10.2514/6.2019-2241.

[53] Yoo, C. S., Richardson, E. S., Sankaran, R., and Chen, J. H., "A DNS Study of a Turbulent Lifted Ethylene Jet Flame in Highly-Heated Coflow," Proc. Combust. Inst., Vol. 33, 2011, pp. 1619-1627.

[54] Luong, M. B., Luo, Z., Lu, T., Chung, S. H., and Yoo, C. S., "Direct numerical simulations of the ignition of lean primary reference fuel/air mixtures with temperature inhomogeneities,” Combust. Flame, Vol. 160, 2013, pp. 2038-2047. 
[55] Luong, M. B., Lu, T., Chung, S. H., and Yoo, C. S., "Direct numerical simulations of the ignition of a lean biodiesel/air mixture with temperature and composition inhomogeneities at high pressure and intermediate temperature," Combust. Flame, Vol. 161, 2014, pp. 2878-2889.

[56] Luong, M. B., Yu, G. H., Lu, T., Chung, S. H., and Yoo, C. S., "Direct numerical simulations of ignition of a lean $n$-heptane/air mixture with temperature and composition inhomogeneities relevant to HCCI and SCCI combustion," Combust. Flame, Vol. 162,2015 , pp. 4566-4585.

[57] Kim, S. O., Luong, M. B., Chen, J. H., and Yoo, C. S., "A DNS study of the ignition of lean PRF/air mixtures with temperature inhomogeneities under high pressure and intermediate temperature," Combust. Flame, Vol. 162, 2015, pp. 717-726.

[58] Luong, M. B., Yu, G. H., Chung, S. H., and Yoo, C. S., "Ignition of a lean PRF/air mixture under RCCI/SCCI conditions: A comparative DNS study," Proc. Combust. Inst., Vol. 36, 2017, pp. 3623-3631.

[59] Luong, M. B., Yu, G. H., Chung, S. H., and Yoo, C. S., "Ignition of a lean PRF/air mixture under RCCI/SCCI conditions: Chemical aspects," Proc. Combust. Inst., Vol. 36, 2017, pp. 3587-3596.

[60] Luong, M. B., Sankaran, R., Yu, G. H., Chung, S. H., and Yoo, C. S., "On the effect of injection timing on the ignition of lean PRF/air/EGR mixtures under direct dual fuel stratification conditions," Combust. Flame, Vol. 183, 2017, pp. 309-321.

[61] Yu, G. H., Luong, M. B., Chung, S. H., and Yoo, C. S., "Ignition characteristics of a temporally evolving $n$-heptane jet in an iso-octane/air stream under RCCI combustion-relevant conditions,", Combust. Flame, Vol. 208, 2019, pp. $299-312$.

[62] Passot, T., and Pouquet, A., "Numerical simulation of compressible homogeneous flows in the turbulent regime," J. Fluid Mech., Vol. 118, 1987, pp. 441-466.

[63] Bansal, G., and Im, H. G., "Autoignition and front propagation in low temperature combustion engine environments," Combust. Flame, Vol. 158, 2011, pp. 2105-2112.

[64] Pal, P., Valorani, M., Arias, P. G., Im, H. G., Wooldridge, M. S., Ciottoli, P. P., and Galassi, R. M., "Computational characterization of ignition regimes in a syngas/air mixture with temperature fluctuations," Proc. Combust. Inst., Vol. 36, 2017, pp. 3705-3716.

[65] Kalghatgi, G., "Knock onset, knock intensity, superknock and preignition in spark ignition engines," Int. J. Engine Res., Vol. 19, 2017, pp. 7-20.

[66] Wang, L., and Peters, N., "The length-scale distribution function of the distance between extremal points in passive scalar turbulence," J. Fluid Mech., Vol. 554, 2006, pp. 457-475.

[67] Luong, M. B., and Im, H. G., "Effects of low-temperature chemistry on detonation under engine-relevant conditions," Submitted to Proc. Combust. Inst., 2022. 